\title{
Replication Study of Genome-Wide Association Study of Platelet Count in Korean Health Examinees (HEXA) Cohort
}

\author{
Min-Ji Jeoung ${ }^{1,, *}$, Yoon-Ji Kong ${ }^{1,, *}$, Sangjung Park ${ }^{1, \uparrow, * *}$ and Hyun-Seok Jin ${ }^{1,2, ;, * *}$ \\ ${ }^{1}$ Department of Biomedical Laboratory Science, College of Life and Health Sciences, \\ Hoseo University, Asan, Chungnam 31499, Korea \\ ${ }^{2}$ The Research Institute for Basic Sciences, Hoseo University, Asan, Chungnam 31499, Korea
}

\begin{abstract}
Platelets are derived from fragments formed in the cytoplasm of bone marrow megakaryocytes. Platelet count (PLT) can be altered by factors such as platelet production, destruction, and inflammation. In a previous study, the significant single nucleotide polymorphisms (SNP) were reported by the genome-wide association study (GWAS) for PLT in Koreans. In this study, it was confirmed whether significant SNPs were replicated in the HEXA (The Health Examinees) cohort. As a result, the SNPs of the THPO (rs6141), BAK1 (rs210314, rs9296095), GGNBP1 (rs75080135), ACAD10 (rs6490294), and $A B C C 4$ (rs4148441) were significantly correlated with PLT $\left(P<10^{-8}\right)$. At the same time, it was confirmed that the direction of influence was the same according to the genotype. In conclusion, it can be seen that common SNPs are associated with the platelet count regardless of the cohort for Koreans.
\end{abstract}

Key Words: GWAS, Platelet, HEXA cohort, SNP

혈소판은 혈액 응고과정에서 중요한 역할을 하는 성분 중 하나로, 골수계 거핵세포로 부터 유래한다. 혈소판은 접착, 응집 등의 역할을 가질 뿐만 아니라 죽상 경화증 및 동맥경화의 원인이 되기도 한다(Soranzo et al., 2009). 혈소판 수치는 지혈과 그 외 임상 증상에 관여하는 지표 이며 혈전이나 출혈성 질환을 진단하는데 사용할 수 있 다(Oh et al., 2014). 외상이나 감염과 같은 자극이 있을 경 우 혈소판 수가 적으면 출혈성 질환을 일으킬 수 있으며, 반대로 혈소판 수가 높으면 골수 질환을 야기할 수 있다 (Wang et al., 2017). 혈소판이 생성되기 위하여 골수 내 거 핵세포의 성숙이 필요한데, 이때 TPO (Thrombopoietin)의
자극이 필요하다. TPO는 거핵세포 표면의 수용체에 결합 하여 거핵세포의 성숙과 분화를 유도할 수 있다. 이러한 $\mathrm{TPO}$ 의 생성과 $\mathrm{TPO}$ 수용체에 선천적으로 유전적인 문제 가 있을 경우, 혈소판 생성에 영향을 줄 수 있다.

이러한 혈소판 수치(Platelet count, PLT)는 인종이나 성별 에 따라 차이가 나지만, 개인의 유전적 배경에도 영향을 받고 있다(Bain, 1996; Buckley et al., 2000; Eicher et al., 2018). 또한, 이전 연구에서 혈소판 수치는 염증 및 혈소판 반응 성(reactivity)과 연관성이 있는 것으로 나타났다(Bessman et al., 1981; Järemo et al., 2000). 따라서 혈소판 수와 연관된 유전적 요인을 연구함으로써 혈액학적 특성을 이해하는데

Received: August 18, 2021 / Revised: September 14, 2021 / Accepted: September 14, 2021

*Undergraduate student, ${ }^{* *}$ Professor.

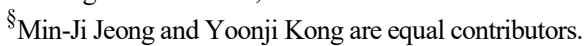

${ }^{\dagger}$ Corresponding author: Sangjung Park. Department of Biomedical Laboratory Science, College of Life and Health Sciences, Hoseo University, 20 Hoseo-ro 79 Beon-gil, Asan-si, Chungcheongnam-do 31499, Korea.

Tel: +82-41-540-9967, Fax:+82-41-540-9997, e-mail: sangjung@hoseo.edu

${ }^{\dagger}$ Corresponding author: Hyun-Seok Jin. Department of Biomedical Laboratory Science, College of Life and Health Sciences, Hoseo University, 20, Hoseo-ro 79 beon-gil, Baebang-eup, Asan-si, Chungnam 31499, Korea.

Tel: +82-41-540-9968, Fax: +82-41-540-9997, e-mail: jinhs@hoseo.edu

() The Korean Society for Biomedical Laboratory Sciences. All rights reserved.

(c) This is an Open Access article distributed under the terms of the Creative Commons Attribution Non-Commercial License (http:/creativecommons.org/licenses/by-nc/3.0/) which permits unrestricted non-commercial use, distribution, and reproduction in any medium, provided the original work is properly cited. 
도움을 주고 관련 질환의 병리 기전에 기반한 치료법을 개발하는데 도움을 줄 수 있다(Chami and Lettre, 2014).

혈액학적 특성에 대한 전장유전체연구(Genome-wide association study, GWAS)들은 활발히 진행되고 있고 다 양한 결과가 발표되었다(Kamatani et al., 2010; Chen et al., 2013). 그 중에서 Oh et al.에서는 8,842명의 한국인을 대상 으로 한 KARE (Korean Association REsource) 코호트 자료 를 활용하여 혈소판 수치(PLT)에 대한 전장유전체연구 결과를 발표하였다(Oh et al., 2014). 따라서 본 연구에서는 앞선 연구 논문에서 대상이 되는 한국인 코호트와는 다 른 HEXA (The Health Examinees) 코호트 자료를 활용하여 혈소판 수치에 대한 전장유전체연구를 수행하고 통계적 유의성을 보인 유전변이들에 대해서는 또한, 전세계의 전 장유전체연구결과 데이터베이스인 GWAS catalog (https:// www.ebi.ac.uk/gwas)에서 제공하는 결과와 비교해 보고자 하였다. 유전형 정보는 호서대학교와 질병관리청 $(\mathrm{KDCA})$ 에서 연구윤리 승인을 받은 후 수행되었다(IRB approval no.: 1041231-150811-BR-034-03).

연구대상자는 한국인 유전체 역학 조사 사업(Korean Genome and Epidemiology Study; KoGES)의 일환인 HEXA 코호트 자료를 분양 받아 활용하였다(KBN-2019-004). HEXA 코호트 자료는 40세 이상의 남녀를 모집하였으 며 28,455 명의 유전형 자료를 분석하였다. 유전형 분석 은 K-CHIP consortium에서 제공하는 Affymetrix Axiom ${ }^{\mathrm{TM}}$ KORV1.0-96 Array (Affymetrix, Santa Clara, CA, USA)인 Korean Chip (K-CHIP)을 사용하여 분석되었다(Moon et al., 2019). 혈액학적 형질들이 조사된 28,455명을 본 연구 의 연구대상자로 선정하였다. 연구대상자의 PLT (Platelet count)에 대하여 GWAS를 수행하였고, 분석 프로그램으로 는 PLINK version 1.07 (http://pngu.-mgh.harvard.edu/ purcell/ plink)을 이용하였다. 이때 분석에 사용된 전체 $\mathrm{SNP}$ 은 462,531개였고, 통계적 유의성은 Bonferroni correction을 기 준으로 $\left(P<10^{-8}\left(462,531 / 0.05=10^{-8}\right)\right.$ 설정하였다. PLT에 대한 상관 분석은 additive 유전 모델을 기준으로 분석하 였고, PLT에 영향을 줄 수 있는 나이와 성별은 공변수로 처리하였다. SNP들의 염색체 상의 위치는 UCSC Genome browser on human Feb, 2009 (Genome Reference Consortium Human Build 37)를 기준으로 하였다. 혈소판 수치에 대 한 전장유전체분석(GWAS) 결과는 Haploview version 4.2 (Whitehead Institute for Biomedical Research, Cambridge, MA, USA) 프로그램을 이용하여 Manhattan plot으로 나 타내었다. 또한, 유의성 있는 유전변이들이 유전체 상의 reginal plot을 확인하기 위해 LocusZoom Version 1.1 (http:// csg.sph.umich.edu/locuszoom)이라는 웹 프로그램을 사용 하여 $\mathrm{SNP}$ 들 간의 recombination rate $(\mathrm{Cm} / \mathrm{Mb})$ 와 $r^{2}$ 를 확인 할 수 있었다. 또한, 전장유전체분석 결과 유의성을 보인 $\mathrm{SNP}$ 들을 기 발표된 GWAS catalog의 결과와 비교하여 PLT와 상관성을 보였던 SNP들을 선별하였다.

한국인 $\mathrm{HEXA}$ 코호트를 대상으로 전장유전체분석을 시 행한 결과 Bonferroni correction $\left(P<10^{-8}\right)$ 을 만족하는 유의 한 $\mathrm{SNP}$ 들에 해당하는 위치에 존재하는 유전자는 총 32 개 였다(supplementary Table 1). 32 개의 유전자 중 5 개의 유전

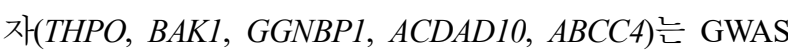
catalog를 확인한 결과 혈소판과 유의성을 보인 결과가 있었다(Table 1). 5 개의 유전자 영역에 포함되며 유의성을 보인 SNP은 THPO 유전자의 rs6141, BAK1 유전자의 rs210314 , rs9296095, GGNBP1 유전자의 rs75080135, $A C A D 10$ 유전자의 rs6490294, $A B C C 4$ 유전자의 rs4148441로 총 6개 이다. 전체 462,531 개의 $\mathrm{SNP}$ 에 대한 전장유전체분석 결 과를 Manhattan plot으로 나타냈고 유의성 있는 6개의 $\mathrm{SNP}$ 들을 표시하였다(Fig. 1). 가장 높은 유의 수준을 보이 는 rs9296095 $\left(P=1.07 \times 10^{-19}\right)$ 는 이번 연구 결과에서 회 귀계수(regression coefficient; Beta)와 표준오차(standard error; $\mathrm{SE}$ )가 $5.46 \pm 0.60$ 으로 나타나 minor allele인 $\mathrm{C}$ 염기를 보 유할수록 혈소판 수치가 높은 경향을 보여주고 있었다. rs9296095는 KARE 코호트 자료를 기반으로 한 이전 연 구에서도 발표되었던 $\mathrm{SNP}$ 이었는데, 본 연구 결과에서 재 현성을 확인할 수 있었다(Oh et al., 2014). rs6141, rs210314, rs75080135, rs6490294, rs4148441은 본 연구에서 혈소판 수 치와 관련하여 한국인에서 처음으로 발굴된 $\mathrm{SNP}$ 들이다.

한국인 HEXA 코호트의 상관성 분석 결과와 GWAS catalog 데이타베이스에서 혈소판 수치에 대한 내용을 비 교해 보았을 때 rs6141, rs9296095, rs75080135는 minor allele를 보유하였을 때 혈소판 수치 변화의 방향성이 일 치하였다. 한국인 HEXA 코호트에서는 $\mathrm{rs} 4148441(P=$ $\left.9.37 \times 10^{-10}\right)$ 은 $\mathrm{A}$ 염기를 보유할 때 Beta와 $\mathrm{SE}$ 값이 -3.73 \pm 0.61 로 나타났고 GWAS catalog에서는 G 염기를 보유할 때 Platelets count unit이 4.12 [2.94 5.29]로 나타나 염기의 기준이 동일할 경우 혈소판 수치의 방향성이 일치하는 것을 알 수 있었다. $\operatorname{rs6490294}\left(P=6.92 \times 10^{-11}\right)$ 의 경우에 는 인종별로 염기변이의 차이가 있는 특수한 $\mathrm{SNP}$ 인데, 한국인을 비롯한 중국인, 일본인에서는 $\mathrm{C}$ 염기의 다형성 이 관찰되고, 서양인에서는 $\mathrm{A}$ 염기의 다형성이 관찰된다 는 특성을 보이고 있다. 본 연구 결과에서는 한국인들이 
Table 1. Comparison of identified SNPs for platelet count (PLT) in GWAS catalog and HEXA cohort

\begin{tabular}{|c|c|c|c|c|c|c|c|c|c|}
\hline \multirow{2}{*}{ CHR } & \multirow{2}{*}{ GENE } & \multirow{2}{*}{ SNP } & \multirow{2}{*}{$\begin{array}{l}\text { Minor/Major } \\
\text { allele }\end{array}$} & \multicolumn{2}{|c|}{ HEXA result } & \multirow{2}{*}{ EA } & \multicolumn{2}{|c|}{ GWAS catalog } & \multirow{2}{*}{ Ref } \\
\hline & & & & Beta \pm SE & $P$-value & & Platelets count unit & $P$-value & \\
\hline \multirow[t]{3}{*}{3} & THPO & rs6141 & $\mathrm{T} / \mathrm{C}$ & $3.02 \pm 0.50$ & $1.24 \times 10^{-9}$ & $\mathrm{~T}$ & $0.08[0.052 \sim 0.100]$ & $5.00 \times 10^{-11}$ & Kamatani Y \\
\hline & & & & & & $\mathrm{T}$ & $2.47[1.57 \sim 3.36]$ & $6.00 \times 10^{-8}$ & Gieger C \\
\hline & & & & & & $\mathrm{T}$ & $0.06[0.056 \sim 0.073]$ & $7.00 \times 10^{-50}$ & Kanai M \\
\hline \multirow[t]{6}{*}{6} & $B A K 1$ & rs210134 & $\mathbf{A} / \mathrm{G}$ & $-3.36 \pm 0.55$ & $8.86 \times 10^{-10}$ & $\mathrm{G}$ & $-8.92[5.82 \sim 12.02]$ & $2.00 \times 10^{-8}$ & $\mathrm{Li} \mathrm{J}$ \\
\hline & & & & & & $\mathrm{G}$ & $-6.16[4.63 \sim 7.69]$ & $2.00 \times 10^{-15}$ & Qayyum R \\
\hline & & & & & & A & $-4.94[3.25 \sim 6.63]$ & $9.00 \times 10^{-9}$ & Schick U \\
\hline & & & & & & $\mathrm{G}$ & $4.96[4.18 \sim 5.73]$ & $7.00 \times 10^{-36}$ & Gieger C \\
\hline & & & & & & $\mathrm{A}$ & $4.66[\mathrm{NR}]$ & $6.00 \times 10^{-8}$ & Shameer K \\
\hline & & & & & & G & $5.73[4.63 \sim 6.83]$ & $2.00 \times 10^{-24}$ & Wojcik G \\
\hline \multirow[t]{2}{*}{6} & $B A K 1$ & rs9296095 & $\mathbf{C} / \mathrm{T}$ & $5.46 \pm 0.60$ & $1.07 \times 10^{-19}$ & $\mathrm{C}$ & $4.8[2.51 \sim 7.09]$ & $1.00 \times 10^{-15}$ & Oh J \\
\hline & & & & & & - & $5.46[4.33 \sim 6.58]$ & $2.00 \times 10^{-21}$ & Wojcik G \\
\hline 6 & $G G N B P 1$ & rs75080135 & $\mathrm{C} / \mathrm{A}$ & $5.58 \pm 0.60$ & $2.80 \times 10^{-20}$ & $\mathrm{C}$ & $0.1[0.093 \sim 0.111]$ & $6.00 \times 10^{-101}$ & Astle W \\
\hline \multirow[t]{2}{*}{12} & $A C A D 10$ & rs6490294 & $\mathrm{C} / \mathrm{A}$ & $-4.29 \pm 0.66$ & $6.92 \times 10^{-11}$ & A & $-4.38[2.91 \sim 5.85]$ & $5.00 \times 10^{-9}$ & Qayyum R \\
\hline & & & & & & - & 2.99 [1.92 4.07] & $5.00 \times 10^{-8}$ & Wojcik G \\
\hline \multirow[t]{2}{*}{13} & $A B C C 4$ & rs4148441 & $\mathbf{A} / \mathrm{G}$ & $-3.73 \pm 0.61$ & $9.37 \times 10^{-10}$ & $\mathrm{G}$ & 4.12 [2.94 5.29] & $7.00 \times 10^{-12}$ & Gieger C \\
\hline & & & & & & - & $3.65[2.09 \sim 5.21]$ & $5.00 \times 10^{-6}$ & Wojcik G \\
\hline
\end{tabular}

The $P$-values lower than the genome wide association study significance level $\left(P<10^{-8}\right)$. Abbreviations: CHR, chromosome; EA, effect allele; HEXA, The health examinees; se, standard error, SNP, single nucleotide polymorphism. The SNP positions are based on UCSC Genome Browser on Human Feb. 2009 (GRCh37/hg19). The beta \pm se of HEXA result is based on the minor allele

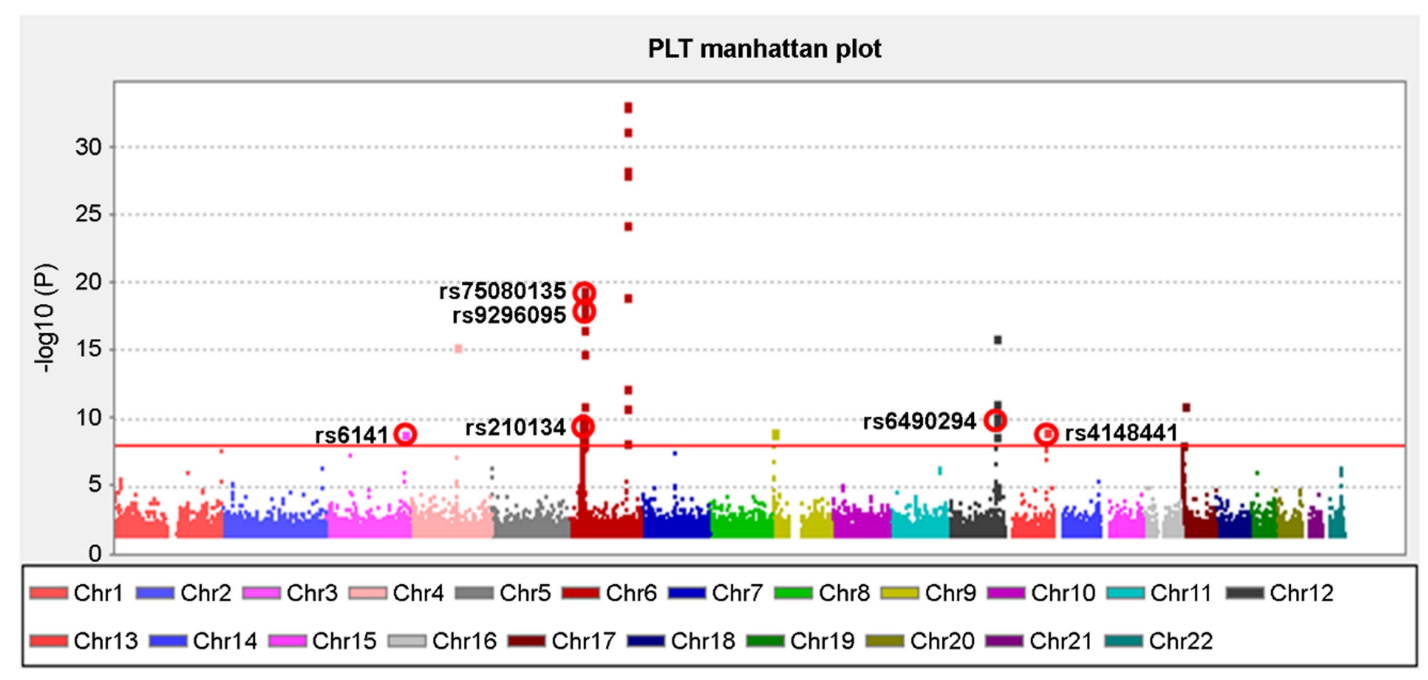

Fig. 1. Manhattan plot of genome-wide association study (GWAS) for platelet count (PLT) in HEXA cohort. The highest $P$-value is single nucleotide polymorphism(SNP) in chromosome 6. Nine genomic regions contain SNPs that exceed the genome-wide significance threshold of $P$-value $\left(1 \times 10^{-8}\right)$. The red circles are SNPs associated with PLT that were repeatedly identified in this study.

C 염기를 보유할 때 $-4.29 \pm 0.66$ 이고, GWAS catalog에 등 록된 논문 기준에서는 A 염기를 보유할 경우 -4.38 (2.91 $5.85)$ 로 나타나 결과적으로 기준참조서열과는 다른 변이
가 있을 때 혈소판 수치를 낮게 하는 경향성을 보인다는 것에서는 일치하는 것을 알 수 있었다(Table 1). Wojcik 의 발표 논문(Wojcik et al., 2019)은 여러 민족들을 통합하 
(A) THPO

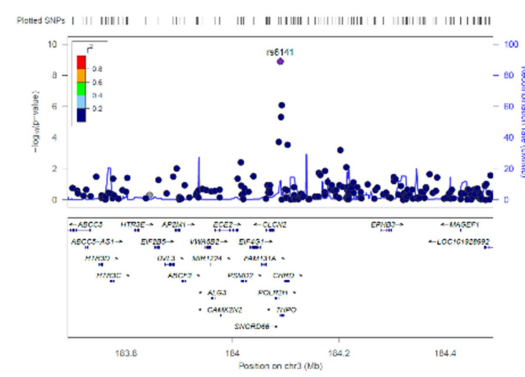

(D) GGNBP1

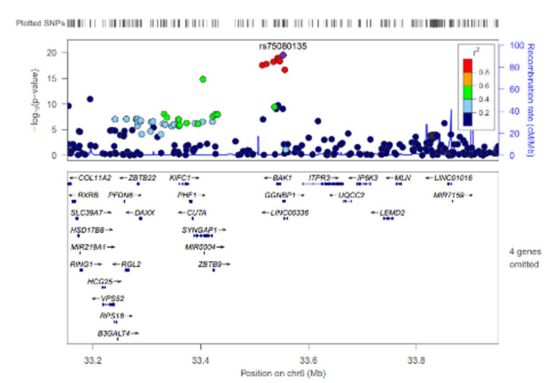

(B) $B A K 1$

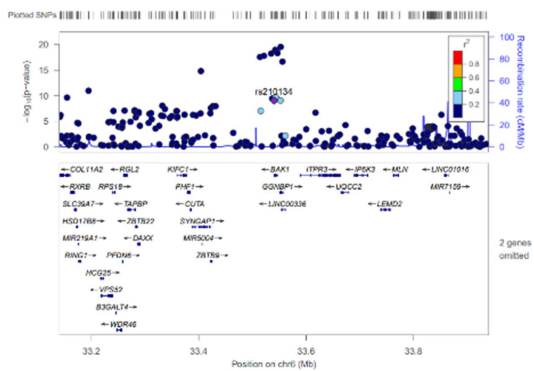

(C) $B A K 1$

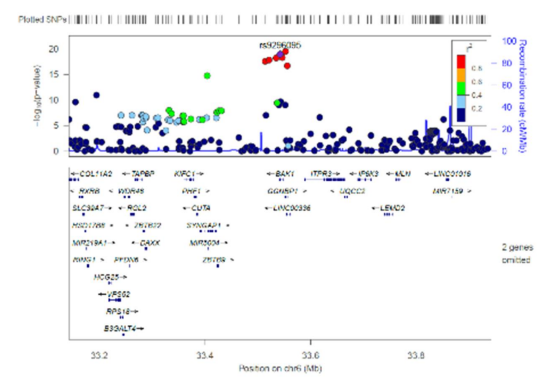

(F) $A B C C 4$
(E) ACAD10

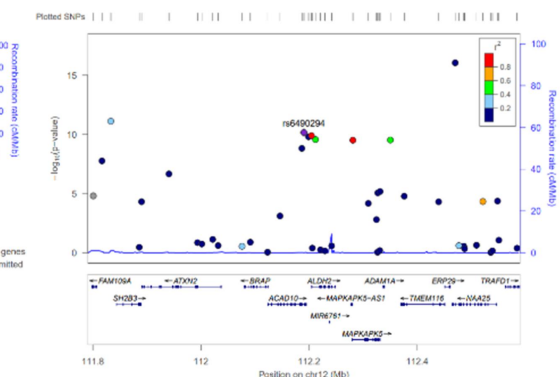

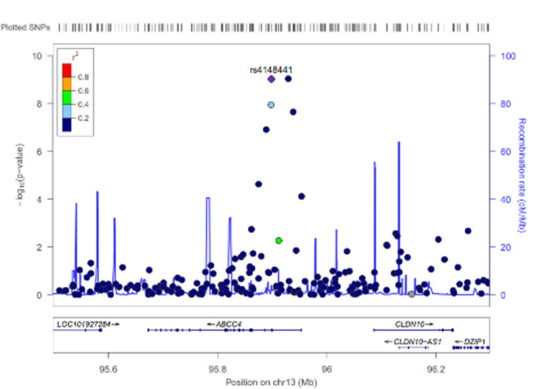

Fig. 2. Regional plots of six discovered variants. Regional plot of six discovered variants (A-F). These plots showing the association signals in the region of THPO on chromosome 3 (A), BAKl on chromosome 6 (B), (C), GGNBP1 on chromosome 6 (D), ACAD10 on chromosome 12(E), and ABCC4 on chromosome 13(F).

여 분석한 논문으로 인종이나 민족들 마다 minor allele의 빈도와 염기의 차이가 있기 때문에 특정 염기로 명확하 게 표기하지는 못하였다(Table 1).

LocusZoom 프로그램을 사용하여 GWAS 유의 수준을 만족하는 6개의 SNP들의 주변의 SNP들과의 recombination rate $(\mathrm{Cm} / \mathrm{Mb})$ 와 $r^{2}$ 를 나타내는 regional plot으로 나 타내었는데(Fig. 2), 그 기준은 hg19 version ASN (Asian population)으로 하였다. 자주색 다이아몬드는 regional plot 상에서 가장 높은 유의성을 보이는 SNP이다. 가장 유의 한 $\mathrm{SNP}$ 과 연관되어 있으면서 $r^{2}$ 값이 높은 $\mathrm{SNP}$ 들은 붉 은색으로 표시된다. rs210134, rs75080135, rs6490294는 주변 에 붉은색으로 표시된 SNP들이 포진되어 서로 간에 연관 되어 있음을 알 수 있다.

$T H P O$ 유전자는 혈소판 성숙과정에서 거핵세포의 증 식과 분화를 조절하는 혈소판형성인자(TPO) 단백질을 코 당한다(Larsen et al., 2017; Cornish et al., 2020). TPO는 TPO 수용체에 결합하여 혈소판 생산을 자극한다(Kuter 2013; Hitchcock and Kaushansky, 2014). 전 연구에 따르면 THPO 유전자 돌연변이는 TPO 단백질의 번역을 증가시켜 TPO 수용체와의 신호전달 경로를 비정상적으로 활성화시킨다.
그 결과 거핵세포의 과잉 생산과 혈소판 수를 증가시켜 본태성 혈소판 감소증을 일으킬 수 있다(Ghilardi et al., 1998; Wiestner et al., 1998; Ghilardi and Skoda RC, 1999; Majka et al., 2002). 따라서 $T H P O$ 에 속한 SNP 염기에 따라 전사 인자 또는 단백질에 미치는 영향에 차이가 있을 것이라 예상되고, 이는 TPO 단백질 번역에 차이를 불러와 PLT에 영향을 미쳤을 것으로 예상한다. 혈소판은 효율적인 메커 니즘을 통해 매일 수백억 개가 순환과정에서 제거된다. 미토콘드리아 막 투과성(MMP)은 BCL2 단백질에 의해 세포자멸사를 통제한다(Kroemer et al., 2007; Suhaili et al., 2017; Peña-Blanco and García-Sáez, 2018). 즉, BCL2 단백질 계열의 일원인 $B A K 1$ 유전자는 세포사멸 조절자 역할을 한다(Kroemer et al., 2007; Peña-Blanco and García-Sáez, 2018; $\mathrm{Yu}$ et al., 2019). BAK1의 불활성화와 BCL2 간의 상호작용 은 미토콘드리아의 제한적인 세포자멸사를 유발하여 혈 소판 감소증을 유발할 수 있다(Kroemer et al., 2007; Suhaili et al., 2017; Peña-Blanco and García-Sáez, 2018). GGNBP1은 GGN1 단백질로 이루어진 pseudogene이다. 이 유전자는 인간에게 단일 유사 유전자로 혈소판 수와의 메커니즘은 아직 밝혀지지 않았다(Zhang et al., 2005; Jamsai et al., 2008). 
$A C A D 10$ 유전자의 돌연변이는 지방을 분해하는데 중요 한 Acyl-CoA Dehydrogenase (MCAD) 효소의 결핍을 유 발한다(Merritt and Chang, 2000). MCAD 효소의 결핍은 HELLP 증후군을 일으킬 수 있는데, 이는 임신중독증에 용혈 hemolysis $(\mathrm{H})$, 간기능장애 elevated liver enzymes $(\mathrm{EL})$, 혈소판 감소 low platelets (LP)를 합병하여 붙여진 이름이 다(Shekhawat et al., 2005). 따라서 혈소판과 상관관계를 가져 유전적 다형성에 따라 혈소판 수에 영향을 미칠 것 으로 생각된다. $\mathrm{ABCC} 4$ 수용체는 인간 혈소판의 델타-과 립에서 발현되고 $\mathrm{ADP}$ 수송에 관여한다(Jedlitschky et al., 2010). 델타-과립에는 $\mathrm{ADP}, \mathrm{ATP}$, 세로토닌, $\mathrm{Ca}^{2+}$ 등을 많이 함유하고 있으며 지혈을 위해 혈소판을 응집시킨다. 따라 서 $\mathrm{ABCC} 4$ 의 결함은 혈소판이 정상 델타-과립의 조립과 콜라겐과의 유도 응집을 손상을 시킨다(Jedlitschky et al., 2010; Cheepala et al., 2015).

최근 특정 질병 또는 표현형과 유전적 다형성 사이에 상관 관계를 분석하여 질병 발병에 미치는 유전적인 요 인을 동정하는 연구들이 활발히 진행되고 있다(Kroemer et al., 2007; Eicher et al., 2018; Gill et al., 2018). 본 연구는 기존에 KARE 코호트 자료를 토대로 발표된 결과와 다른 연구대상자인 HEXA 코호트 자료를 활용하여 혈소판 수 치와 연관성이 나타난 유전적 다형성을 발굴하고, 재현성 을 확인하였다. 그 결과, $B A K 1$ 유전자의 rs9296095는 두 코호트에서 모두 혈소판 수치와 연관된 $\mathrm{SNP}$ 임을 밝혀 재 현성이 확인되었다. 또한, $T H P O$ 유전자의 $\mathrm{rs} 6141, B A K 1$ 유전자의 rs210134, $G G N B P 1$ 유전자의 rs75080135, $A B C C 4$ 유전자의 rs4148441은 한국인에서 처음으로 혈소판 수와 관련하여 발굴된 SNP이었다. 따라서 HEXA 코호트 자료 를 활용한 본 연구 결과를 통해 혈소판 수에 영향을 미칠 수 있는 유전인자들을 다시 한 번 재확인하고 새로운 가 능성 있는 유전변이들을 제시할 뿐만 아니라 해당 유전 자들의 혈소판과 관련된 세포생물학적 기전과의 관련성 을 통해 혈소판 관련 질환에 대한 유전학적 이해를 증진 시킬 것으로 기대한다.

\section{ACKNOWLEDGEMENT}

This work was supported by the Basic Science Research Program through the National Research Foundation of Korea (NRF) funded by the Ministry of Education [NRF2017R1D1A3B03034752].

\section{CONFLICT OF INTEREST}

All authors declare no competing interests.

\section{REFERENCES}

Astle WJ, Elding H, Jiang T, Allen D, Ruklisa D, Mann AL, Mead D, Bouman H, Riveros-Mckay F, Kostadima MA, Lambourne JJ, Sivapalaratnam S, Downes K, Kundu K, Bomba L, Berentsen K, Bradley JR, Daugherty LC, Delaneau O, Freson K, Garner SF, Grassi L, Guerrero J, Haimel M, Janssen-Megens EM, Kaan A, Kamat M, Kim B, Mandoli A, Marchini J, Martens JHA, Meacham S, Megy K, O'Connell J, Petersen R, Sharifi N, Sheard SM, Staley JR, Tuna S, van der Ent M, Walter K, Wang SY, Wheeler E, Wilder SP, Iotchkova V, Moore C, Sambrook J, Stunnenberg HG, Di Angelantonio E, Kaptoge S, Kuijpers TW, Carrillo-de-Santa-Pau E, Juan D, Rico D, Valencia A, Chen L, Ge B, Vasquez L, Kwan T, Garrido-Martín D, Watt S, Yang Y, Guigo R, Beck S, Paul DS, Pastinen T, Bujold D, Bourque G, Frontini M, Danesh J, Roberts DJ, Ouwehand WH, Butterworth AS, Soranzo N. The Allelic Landscape of Human Blood Cell Trait Variation and Links to Common Complex Disease. Cell. 2016. 167: 1415-1429.

Bain BJ. Ethnic and sex differences in the total and differential white cell count and platelet count. J Clin Pathol. 1996. 49: 664-666.

Bessman JD, Williams LJ, Gilmer PR Jr. Mean platelet volume. The inverse relation of platelet size and count in normal subjects, and an artifact of other particles. Am J Clin Pathol. 1981. 76: 289-293.

Buckley MF, James JW, Brown DE, Whyte GS, Dean MG, Chesterman CN, Donald JA. A novel approach to the assessment of variations in the human platelet count. Thromb Haemost. 2000. 83: 480-484.

Chami N, Lettre G. Lessons and Implications from Genome-Wide Association Studies (GWAS) Findings of Blood Cell Phenotypes. Genes (Basel). 2014. 5: 51-64.

Cheepala SB, Pitre A, Fukuda Y, Takenaka K, Zhang Y, Wang Y, Frase S, Pestina T, Gartner TK, Jackson C, Schuetz JD. The $\mathrm{ABCC} 4$ membrane transporter modulates platelet aggregation. Blood. 2015. 126: 2307-2319.

Chen Z, Tang H, Qayyum R, Schick UM, Nalls MA, Handsaker R, Li J, Lu Y, Yanek LR, Keating B, Meng Y, van Rooij FJ, Okada Y, Kubo M, Rasmussen-Torvik L, Keller MF, Lange 
L, Evans M, Bottinger EP, Linderman MD, Ruderfer DM, Hakonarson H, Papanicolaou G, Zonderman AB, Gottesman O; BioBank Japan Project; CHARGE Consortium, Thomson C, Ziv E, Singleton AB, Loos RJ, Sleiman PM, Ganesh S, McCarroll S, Becker DM, Wilson JG, Lettre G, Reiner AP. Genome-wide association analysis of red blood cell traits in African Americans: the COGENT Network. Hum Mol Genet. 2013. 22: 2529-2538.

Cornish N, Aungraheeta MR, FitzGibbon L, Burley K, Alibhai D, Collins J, Greene D, Downes K; NIHR BioResource, Westbury SK, Turro E, Mumford AD. Monoallelic loss-of-function THPO variants cause heritable thrombocytopenia. Blood Adv. 2020. 4: 920-924.

Eicher JD, Lettre G, Johnson AD. The genetics of platelet count and volume in humans. Platelets. 2018. 29: 125-130.

Ghilardi N, Skoda RC. A single-base deletion in the thrombopoietin (TPO) gene causes familial essential thrombocythemia through a mechanism of more efficient translation of TPO mRNA. Blood. 1999. 94: 1480-1482.

Ghilardi N, Wiestner A, Skoda RC. Thrombopoietin production is inhibited by a translational mechanism. Blood. 1998. 92: 40234030.

Gill D, Monori G, Georgakis MK, Tzoulaki I, Laffan M. Genetically Determined Platelet Count and Risk of Cardiovascular Disease. Arterioscler Thromb Vasc Biol. 2018. 38: 2862-2869.

Hitchcock IS, Kaushansky K. Thrombopoietin from beginning to end. Br J Haematol. 2014. 165: 259-268.

Jamsai D, Bianco DM, Smith SJ, Merriner DJ, Ly-Huynh JD, Herlihy A, Niranjan B, Gibbs GM, O'Bryan MK. Characterization of gametogenetin 1 (GGN1) and its potential role in male fertility through the interaction with the ion channel regulator, cysteine-rich secretory protein 2 (CRISP2) in the sperm tail. Reproduction. 2008. 135: 751-759.

Järemo P, Hansson G, Nilsson O. Elevated inflammatory parameters are associated with lower platelet density in acute myocardial infarctions with ST-elevation. Thromb Res. 2000. 100: 471478.

Jedlitschky G, Cattaneo M, Lubenow LE, Rosskopf D, Lecchi A, Artoni A, Motta G, Niessen J, Kroemer HK, Greinacher A. Role of MRP4 (ABCC4) in platelet adenine nucleotide-storage: evidence from patients with delta-storage pool deficiencies. Am J Pathol. 2010. 176: 1097-1103.

Kamatani Y, Matsuda K, Okada Y, Kubo M, Hosono N, Daigo Y, Nakamura Y, Kamatani N. Genome-wide association study of hematological and biochemical traits in a Japanese population.
Nat Genet. 2010. 42: 210-215.

Kanai M, Akiyama M, Takahashi A, Matoba N, Momozawa Y, Ikeda M, Iwata N, Ikegawa S, Hirata M, Matsuda K, Kubo M, Okada Y, Kamatani Y. Genetic analysis of quantitative traits in the Japanese population links cell types to complex human diseases. Nat Genet. 2018. 50: 390-400.

Kroemer G, Galluzzi L, Brenner C. Mitochondrial membrane permeabilization in cell death. Physiol Rev. 2007. 87: 99-163.

Kuter DJ. The biology of thrombopoietin and thrombopoietin receptor agonists. Int J Hematol. 2013. 98: 10-23.

Larsen SB, Grove EL, Neergaard-Petersen S, Würtz M, Hvas AM, Kristensen SD. Thrombopoietin and platelet aggregation in patients with stable coronary artery disease. Platelets. 2017. 28: 822-824.

Majka M, Ratajczak J, Villaire G, Kubiczek K, Marquez LA, Janowska-Wieczorek A, Ratajczak MZ. Thrombopoietin, but not cytokines binding to gp130 protein-coupled receptors, activates MAPKp42/44, AKT, and STAT proteins in normal human CD34+ cells, megakaryocytes, and platelets. Exp Hematol. 2002. 30: 751-760.

Merritt JL 2nd, Chang IJ. Medium-Chain Acyl-Coenzyme A Dehydrogenase Deficiency. 2000 Apr 20 [updated 2019 Jun 27]. In: Adam MP, Ardinger HH, Pagon RA, Wallace SE, Bean LJH, Mirzaa G, Amemiya A, editors. GeneReviews ${ }^{\circledR}$ [Internet]. Seattle (WA): University of Washington, Seattle; 1993-2021.

Moon S, Kim YJ, Han S, Hwang MY, Shin DM, Park MY, Lu Y, Yoon K, Jang HM, Kim YK, Park TJ, Song DS, Park JK, Lee JE, Kim BJ. The Korea Biobank Array: Design and Identification of Coding Variants Associated with Blood Biochemical Traits. Sci Rep. 2019. 9: 1382.

Oh JH, Kim YK, Moon S, Kim YJ, Kim BJ. Genome-wide association study identifies candidate Loci associated with platelet count in koreans. Genomics Inform. 2014. 12: 225230.

Peña-Blanco A, García-Sáez AJ. Bax, Bak and beyond mitochondrial performance in apoptosis. FEBS J. 2018. 285 416-431.

Shameer K, Denny JC, Ding K, Jouni H, Crosslin DR, de Andrade M, Chute CG, Peissig P, Pacheco JA, Li R, Bastarache L, Kho AN, Ritchie MD, Masys DR, Chisholm RL, Larson EB, McCarty CA, Roden DM, Jarvik GP, Kullo IJ. A genomeand phenome-wide association study to identify genetic variants influencing platelet count and volume and their pleiotropic effects. Hum Genet. 2014. 133: 95-109. 
Shekhawat PS, Matern D, Strauss AW. Fetal fatty acid oxidation disorders, their effect on maternal health and neonatal outcome: impact of expanded newborn screening on their diagnosis and management. Pediatr Res. 2005. 57: 78R-86R.

Soranzo N, Spector TD, Mangino M, Kühnel B, Rendon A, Teumer A, Willenborg C, Wright B, Chen L, Li M, Salo P, Voight BF, Burns P, Laskowski RA, Xue Y, Menzel S, Altshuler D, Bradley JR, Bumpstead S, Burnett MS, Devaney J, Döring A, Elosua R, Epstein SE, Erber W, Falchi M, Garner SF, Ghori MJ, Goodall AH, Gwilliam R, Hakonarson HH, Hall AS, Hammond N, Hengstenberg C, Illig T, König IR, Knouff CW, McPherson R, Melander O, Mooser V, Nauck M, Nieminen MS, O'Donnell CJ, Peltonen L, Potter SC, Prokisch H, Rader DJ, Rice CM, Roberts R, Salomaa V, Sambrook J, Schreiber S, Schunkert H, Schwartz SM, Serbanovic-Canic J, Sinisalo J, Siscovick DS, Stark K, Surakka I, Stephens J, Thompson JR, Völker U, Völzke H, Watkins NA, Wells GA, Wichmann HE, Van Heel DA, Tyler-Smith C, Thein SL, Kathiresan S, Perola M, Reilly MP, Stewart AF, Erdmann J, Samani NJ, Meisinger C, Greinacher A, Deloukas P, Ouwehand WH, Gieger C. A genome-wide meta-analysis identifies 22 loci associated with eight hematological parameters in the HaemGen consortium. Nat Genet. 2009. 41: 1182-1190.

Suhaili SH, Karimian H, Stellato M, Lee TH, Aguilar MI. Mitochondrial outer membrane permeabilization: a focus on the role of mitochondrial membrane structural organization. Biophys Rev. 2017. 9: 443-457.

Wang JY, Ye S, Zhong H. The role of bone marrow microenvironment in platelet production and their implications for the treatment of thrombocytopenic diseases. Hematology. 2017. 22: 630-639.

Wojcik GL, Graff M, Nishimura KK, Tao R, Haessler J, Gignoux CR, Highland HM, Patel YM, Sorokin EP, Avery CL, Belbin GM, Bien SA, Cheng I, Cullina S, Hodonsky CJ, Hu Y, Huckins LM, Jeff J, Justice AE, Kocarnik JM, Lim U, Lin BM, Lu Y, Nelson SC, Park SL, Poisner H, Preuss MH, Richard MA, Schurmann C, Setiawan VW, Sockell A, Vahi
K, Verbanck M, Vishnu A, Walker RW, Young KL, Zubair N, Acuña-Alonso V, Ambite JL, Barnes KC, Boerwinkle E, Bottinger EP, Bustamante CD, Caberto C, Canizales-Quinteros S, Conomos MP, Deelman E, Do R, Doheny K, FernándezRhodes L, Fornage M, Hailu B, Heiss G, Henn BM, Hindorff LA, Jackson RD, Laurie CA, Laurie CC, Li Y, Lin DY, Moreno-Estrada A, Nadkarni G, Norman PJ, Pooler LC, Reiner AP, Romm J, Sabatti C, Sandoval K, Sheng X, Stahl EA, Stram DO, Thornton TA, Wassel CL, Wilkens LR, Winkler CA, Yoneyama S, Buyske S, Haiman CA, Kooperberg C, Le Marchand L, Loos RJF, Matise TC, North KE, Peters U, Kenny EE, Carlson CS. Genetic analyses of diverse populations improves discovery for complex traits. Nature. 2019. 570: 514518.

Wiestner A, Schlemper RJ, van der Maas AP, Skoda RC. An activating splice donor mutation in the thrombopoietin gene causes hereditary thrombocythaemia. Nat Genet. 1998. 18: 4952.

Yu X, Xu G, Li B, de Souza Vespoli L, Liu H, Moeder W, Chen S, de Oliveira MVV, Ariádina de Souza S, Shao W, Rodrigues B, Ma Y, Chhajed S, Xue S, Berkowitz GA, Yoshioka K, He P, Shan L. The Receptor Kinases BAK1/SERK4 Regulate $\mathrm{Ca}^{2+}$ Channel-Mediated Cellular Homeostasis for Cell Death Containment. Curr Biol. 2019. 29: 3778-3790.e8.

Zhang J, Wang Y, Zhou Y, Cao Z, Huang P, Lu B. Yeast twohybrid screens imply that GGNBP1, GGNBP2 and OAZ3 are potential interaction partners of testicular germ cellspecific protein GGN1. FEBS Lett. 2005. 579: 559-566.

https://doi.org/10.15616/BSL.2021.27.3.187

Cite this article as: Jeoung MJ, Kong YJ, Park S, Jin HS. Replication Study of Genome-Wide Association Study of Platelet Count in Korean Health Examinees (HEXA) Cohort. Biomedical Science Letters. 2021. 27: 187-194. 


\section{Supplementary}

Table 1. Significant gene in GWAS results for platelet count in the HEXA cohort $\left(P<10^{-8}\right)$

\begin{tabular}{|c|c|c|}
\hline No. & CHR & GENE \\
\hline 1 & 3 & THPO \\
\hline 2 & 4 & $E G F$ \\
\hline 3 & 6 & $A L D H 8 A 1$ \\
\hline 4 & & $A L D H 8 A 1$ \\
\hline 5 & & $B A K 1$ \\
\hline 6 & & C6orf15 \\
\hline 7 & & CCHCRI \\
\hline 8 & & $C D S N$ \\
\hline 9 & & CLIC1 \\
\hline 10 & & COL11A2 \\
\hline 11 & & $D D A H 2$ \\
\hline 12 & & $G G N B P 1$ \\
\hline 13 & & $H L A-F$ \\
\hline 14 & & $H L A-F-A S I$ \\
\hline 15 & & KCTD20 \\
\hline 16 & & LINC00336 \\
\hline 17 & & LOC105378010 \\
\hline 18 & & $M C C D 1$ \\
\hline 19 & & PSORSIC1 \\
\hline 20 & & PSORS1C2 \\
\hline 21 & & PSORS1C3 \\
\hline 22 & & SYNGAP1 \\
\hline 23 & 9 & $R C L 1$ \\
\hline 24 & 12 & $A C A D 10$ \\
\hline 25 & & $A L D H 2$ \\
\hline 26 & & LINC02356 \\
\hline 27 & & MAPKAPK5 \\
\hline 28 & & $M A P K-A S 1$ \\
\hline 29 & & $N A A 25$ \\
\hline 30 & & TMEM116 \\
\hline 31 & 13 & $A B C C 4$ \\
\hline 32 & 17 & SMG6 \\
\hline
\end{tabular}

Bonferroni correction $P$-value $\left(P<10^{-8}\right)$. Abbreviations: CHR, chromosome; HEXA, The health examiness; No., number 